\title{
Some Biochemical and Histological Changes during Experimentally Induced Hyperprolactinemia in Male Rabbits
}

\author{
A.A. Yousef, ${ }^{1}$ * ${ }^{*}$ Y.M. Hussein, ${ }^{2}$ and H.A. Heshmat ${ }^{1}$ \\ ${ }^{1}$ Department of Physiology and Biochemistry, Faculty of Veterinary Medicine, \\ Zagazig University, Zagazig, Egypt \\ ${ }^{2}$ Department of Biochemistry, Faculty of Medicine, \\ Zagazig University, Zagazig, Egypt
}

(Received June 6, 1987)

\begin{abstract}
Summary Determination of the effect of prolactin administration on glucose, non-esterified fatty acids, insulin, and liver glycogen concentrations in male rabbit was the aim of the present investigation. Thin sections of livers and testes were also examined microscopically. The results suggested that prolactin administration produced a state of prolactin over secretion. The level of serum glucose showed a significant increase without any significant change in insulin activity. Non-esterified fatty acid level increased in serum while liver glycogen decreased. The histological observations revealed that prolactin administration exerts a degenerative changes in both livers and testes.
\end{abstract}

Key Words: male infertility, hyperprolactinemia, prolactin, carbohydrate metabolism, lipid metabolism

Over-secretion of prolactin has been found to be one of the most important causes of male infertility in humans [1,2] and animals [3, 4]. Very little however has been published about the effects of prolactin on carbohydrate metabolism. However, it was reported that lipid abnormalities were most common in infertile men [5]. It was suggested that non-esterified fatty acid (NEFA) level exerts a direct action at the testicular function in man [6]. It was therefore of interest to study the metabolic effect of prolactin on the levels of glucose, NEFA, and insulin in serum and glycogen concentration in liver. This necessiated the establishment of the effect of prolactin administration on the liver and testis and to find to what extent prolactin was responsible for the hepatic and testicular functions in male rabbits.

*To whom correspondence should be addressed. 


\section{MATERIALS AND METHODS}

Forty native mature male rabbits were obtained from nearby private farm at Zagazig. These animals were apparently healthy, aged 8 to 10 months and weighing from 1.5 to $2 \mathrm{~kg}$. They were divided into 4 groups, each containing 10 male rabbits. All the animals were fed on a mixture of ground wheat, barley, and maize in addition to normal green fodder and were provided with excess water. The first group of animals served as control, whereas the other groups were injected intraperitoneally with daily doses of 300 I.U. of prolactin (National Institute for Biological Standards and Control, Holly Hill, Hampstead) dissolved in $0.3 \mathrm{ml}$ physiological saline. This dose was expressed to induced hyperprolactinemia in male rabbits when given daily for consecutive 7 days as has been suggested in a previous communication [7]. So, the second group, given prolactin for consecutive 7 days; the third group, for consecutive 14 days; while the fourth group, for consecutive 21 days.

At the end of prolactin injections, the animals of each group were then slaughtered, and blood samples collected were left to clot at $37^{\circ} \mathrm{C}$ for $1 \mathrm{~h}$ and centrifuged at 3,000 rpm to separate serum samples. Serum glucose [8] and NEFA [9] levels were assayed by colorimetric methods. Serum prolactin [10] and serum insulin [11] activities were assayed by radioimmunoassay.

Livers and testes of the slaughtered animals were removed and frozen.

Liver glycogen concentration was determined colorimetrically according to the method of Carrol et al. [12]. The organs (livers and testes) were cleared of adhering tissues and washed with physiological saline and examined grossly. Small pieces of these organs were fixed in $10 \%$ neutral buffered formalin. Thin sections were stained with haematoxylin and eosin and examined microscopically [13].

The results were statistically analyzed according to the method of Snedecor and Cochran [14].

\section{RESULTS}

The results obtained on serum prolactin, glucose, insulin, NEFA, and liver

Table 1. Serum levels of prolactin, glucose, insulin, and NEFA and liver glycogen concentration in male rabbits before and after prolactin injections.

\begin{tabular}{lcccc}
\hline \multicolumn{1}{c}{ Item } & $\begin{array}{c}\text { Group I } \\
\text { (Control) }\end{array}$ & $\begin{array}{c}\text { Group II } \\
(1 \text { st week })\end{array}$ & $\begin{array}{c}\text { Group III } \\
\text { (2nd week) }\end{array}$ & $\begin{array}{c}\text { Group III } \\
\text { (3rd week) }\end{array}$ \\
\hline Prolactin $(\mathrm{ng} / \mathrm{ml})$ & $10.5 \pm 1.2$ & $17.6 \pm 3.1^{* *}$ & $20.9 \pm 5.1^{* *}$ & $35.7 \pm 5.4^{* *}$ \\
Glucose $(\mathrm{mg} / \mathrm{dl})$ & $110.2 \pm 5.7$ & $112.6 \pm 7.6$ & $130.3 \pm 8.5^{*}$ & $135.5 \pm 3.3^{*}$ \\
Insulin $(\mu \mathrm{unit} / \mathrm{ml})$ & $60.5 \pm 15.2$ & $60.5 \pm 16.5$ & $60.7 \pm 10.4$ & $61.5 \pm 5.3$ \\
NEFA $(\mathrm{mmol} / \mathrm{liter})$ & $1.00 \pm 0.04$ & $1.05 \pm 0.05$ & $1.06 \pm 0.04$ & $2.10 \pm 0.01^{* *}$ \\
Liver glycogen & $10.2 \pm 2.2$ & $7.2 \pm 1.5^{* *}$ & $3.5 \pm 2.1^{* *}$ & $3.3 \pm 1.1^{* *}$ \\
$\quad(\mathrm{~g} / 100$ g fresh liver) & & & & \\
\hline
\end{tabular}

Means \pm SE are given. ${ }^{* *}$ Highly significant $(p \leq 0.001) ; *$ significant $(p \leq 0.01)$. 


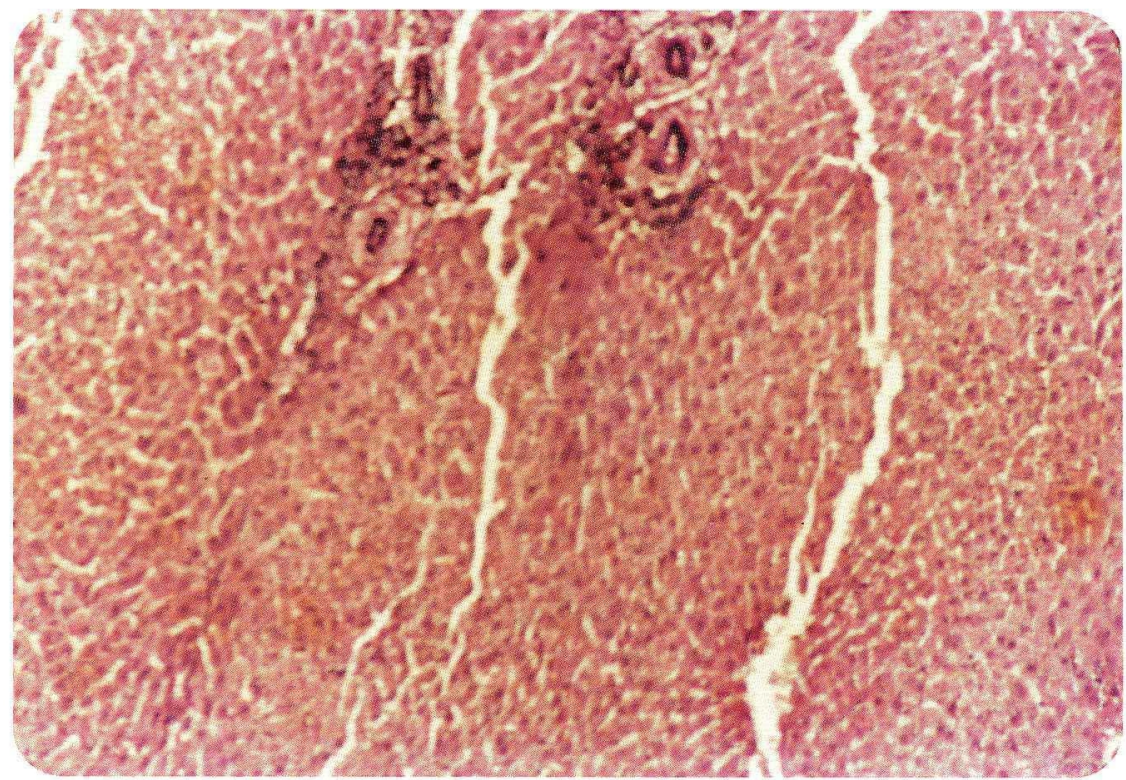

Fig. 1. Photomicrograph of liver from a rabbit after continuous daily administration of prolactin for 3 weeks. Hematoxylin-Eosin staining. Magnification: 220.

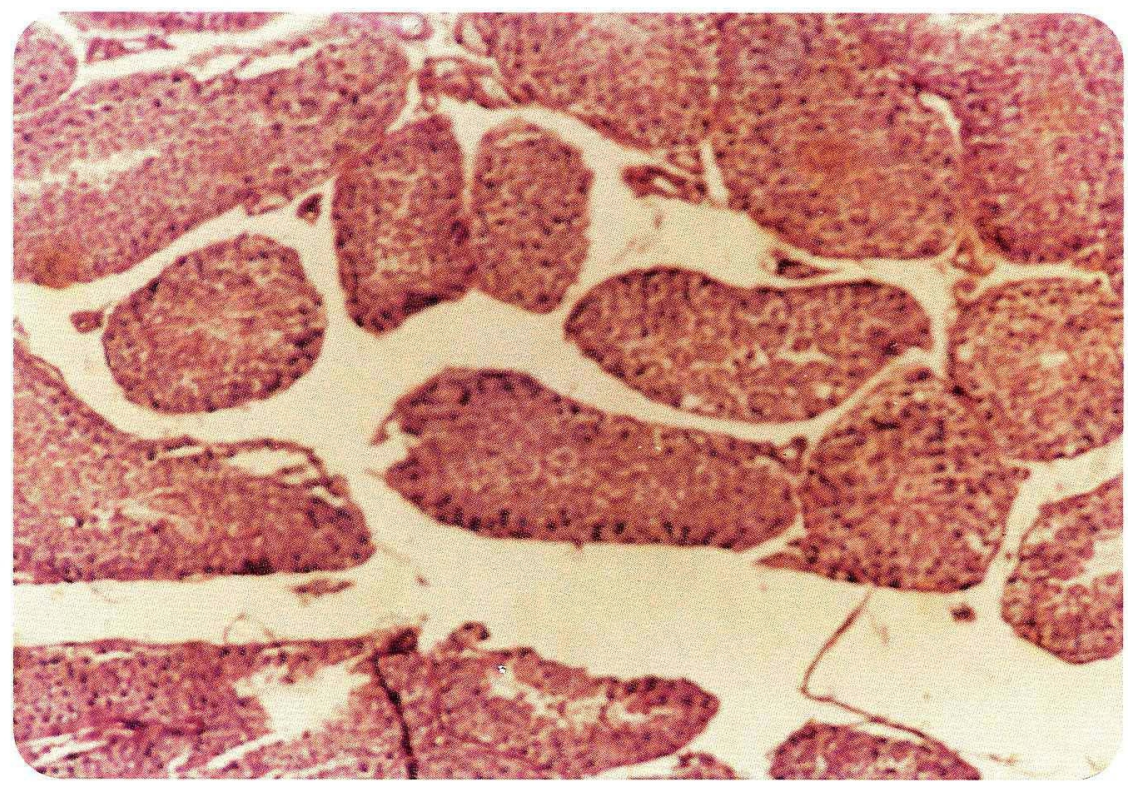

Fig. 2. Photomicrograph of testicle from a rabbit after continuous daily administration of prolactin for 3 weeks. Hematoxylin-Eosin staining. Magnification: 528.

Vol. 4, No. 3, 1988 
glycogen concentrations of the control and prolactin treated male rabbits are summarized in Table 1.

The effect of prolactin injection was markedly seen in the serum prolactin levels. A significant $(p \leq 0.001)$ elevation of serum prolactin level was recorded after one week of prolactin injections which was still higher than that of control after two and three weeks of prolactin injections.

A significant increase of serum glucose levels $(p \leq 0.01)$ was noticed after two and three weeks following prolactin injections.

Serum insulin activities did not show any significant alteration with prolactin administration. NEFA levels showed a significant increase only after three weeks of continuous prolactin treatment $(p \leq 0.001)$.

Liver glycogen concentrations were significantly lower $(p \leq 0.001)$ in all three experimental groups than that of control.

Thus it was clearly evident in our experiment that serum levels of prolactin, glucose, and NEFA and liver glycogen concentrations changed as the period of prolactin administration continued.

The gross morphological and microscopical studies of the liver suggested that continuous daily administration of prolactin enlarged the liver. It became pale in clour and most of the hepatic cells showed vascular degeneration with perivascular oedema. Glisson's capsule showed lymphocytic infiltration (Fig. 1).

In the testis, the testicle was enlarged and the testicular cord surface became white in clour and evaginated. The microscopic picture (Fig. 2) of the testis proved that prolactin administration resulted in intertubular oedema accompanied with hyalin degeneration and coagulative necrosis of primary and secondary spermatids and spermatozoa.

\section{DISCUSSION}

High prolactin levels observed in serum of male rabbits after prolactin administration (Table 1), are in agreement with those reported in different animal species $[3,4,7,15]$. Our values somewhat differed from that reported in other animal species. This difference might be due to the difference in the prolactin doses applied, period of injection, and/or the animal species used.

The increased level of serum glucose in prolactin treated male rabbits confirms the findings by Del-Pozo [16], who reported elevated blood glucose levels in men with hyperprolactinemic infertility. Similar observations were reported in rat [3] and sheep given frequent doses of prolactin [15]. This elevation is probably due to that prolactin stimulates growth hormone $[15,17]$, which could be responsible for the increase of glucose [17]. Moreover, it was demonstrated that the lactogenic hormone prolactin can bring about some of the metabolic and physiological actions of growth hormone as the two hormones share some common biochemical structure [17].

Elevation of serum glucose without any change in insulin confirms the find- 
ings reported in sheep given prolactin hormone [15]. Similar observations were reported in rats deficient in androgens. This might be explained on the basis that prolactin might affect certain factors regulating insulin secretion [18].

The increased level of NEFA after prolactin injections is probably due to increased estrogens or decreased testosterone levels as suggested by many investigators $[5,6,19]$. It was demonstrated $[5,6]$ that men with hyperprolactinemic oligospermic infertility showed significant higher NEFA levels than other fertile men, which was accompanied with decreased level of testosterone and elevated estrogen. Pardon [6] demonstrated that NEFA has a direct effect on testicular function.

The degenerative changes observed in the hepatic tissue after prolactin administration may be attributed to increased binding of prolactin hormone with liver receptors $[20,21]$. It was reported that liver cirrhosis may accompanied with prolactin over-secretion $[20,21]$. Thus, the marked depletion of liver glycogen in our prolactin-injected male rabbits could be attributed to its disturbed synthesis in the liver (Fig. 1).

The testicular abnormalities observed in prolactin treated male rabbits confirmed the findings by many investigators [20-23], who suggested that hyperprolactinemic patients usually suffered from defective sperm maturation, oligospermia, and low androgen production. This may be ascribed to the interference of elevated serum prolactin with spermatogensis through the possibility of prolactin binding to the testis which could interfere with the binding of gonadotropins to the testis or alternatively alter gonadal reaction to gonadotropin [24, 25].

Considering the above facts, we conclude that administration of prolactin stimulates prolactin production and over-secretion of prolactin could be responsible for all the metabolic and functional changes in the liver and testis observed in this study.

We acknowledge the help of Professor Dr. Z.A. Metwally, Department of Pathology, Faculty of Veterinary Medicine, Zagazig University, Zagazig, Egypt.

\section{REFERENCES}

1. Micic, S., Dotlic, R., and Ilis, V. (1985): Serum testosterone and estradiol in infertile men with hyperprolactinemia, in 5th World Congress on Human Reproduction, Athens-Greece, Abstract No. 56.

2. Ainmelk, Y., Belisle, S., Kanadalaft, N., McClure, D., Tetreault, L., and Elhilali, M. (1982): Bromocriptine therapy in oligozoospermic infertile men. Arch. Androl., 8, 135-141.

3. Heshmat, H., Yousef, A.A., and El-Azawy, A. (1987): Hyperprolactinemia in male rat, in 5 th Forum of International Andrology, Paris, Report-I.

4. El-Azawy, A., Yousef, A.A., and Heshmat, H.A., (1987): Hyperprolactinemia in male rat, in 5th Forum of International Andrology, Paris, Report-II.

5. Mas, J., and Padron, R.S. (1985): Plasma lipids and testicular function, in 5th World Congress on Human Reproduction, Athens-Greece, Abstract No. 266.

6. Padron, R.S. (1985): Plasma lipids and testicular function, in 5th World Congress on Human Reproduction, Athens-Greece, Abstract No. 269. 
7. Backry, H., Heshmat, H.A., Yousef, A.A., El-Moussallamy, E. (1987): Toxicological and biochemical studies on bromocriptine as a drug used in treatment of hyperprolactinemia in male rabbits, in Proceeding of 1st Scientific Congress, Future of Rabbit Production in Egypt, Egypt, pp. 20-25.

8. Torlotin, J.C. (1966): Determination of serum glucose. Am. Biol. Clin., 24, 173-175.

9. Duncombe, W.G. (1964): Colorimetric determination of serum NEFA. Biochem. J., 88, 7-10.

10. Mikail, C., Girin, M., and Vange, R. (1970): Radioimmunoassay of prolactin in plasma. Steroids, 15, 333-340.

11. Wilson, S., and Miles, L. (1977): Radioimmunoassay of insulin in plasma, in Handbook of Radioimmunoassay, ed. by Abraham, G.E., and Dekker, M., New York, pp. 257-277.

12. Carrol, N.V., Longley, R.W., and Roe, J.H. (1956): Determination of liver glycogen by use of anthrone reagent. J. Biol. Chem., 220, 583-593.

13. Disbory, B.D., and Rack, I.H. (1970): Histological Laboratory Methods, ed. by Livingstone, E.A.A., Edinburgh and London, pp. 96-130.

14. Snedecor, G.W., and Cochran, W.G. (1976): Statistical Methods (6th ed.), Iowa State University Press, Iowa.

15. Manns, J.G., and Boda, J.M. (1956): Effects of ovine growth hormone and prolactin on non-esterified fatty acids and amino nitrogen in sheep. Endocrinology, 48, 125-131.

16. Del-Pozo, E. (1982): Hyperprolactinemia in man, in Treatment of Male Infertility, ed. by Bain, J., Schill, W.B., and Schwarzstien, L., Springer-Verlag, Berlin, Heidberg, and New York, pp. 71-84.

17. Harper, H., Rodwell, V., and Mayes, P. (1979): Chemistry and functions of hormones II. Pituitary and hypothalamus, in Review of Physiological Chemistry (17th ed.), Lauge Medical Publications, Drawer, Los Atlos, California, pp. 556-568.

18. Hamdy, H., Abdel-Rahman, Y., Makarem, F., Marzouk, M., Mohammady, I., Salem, B., and Haidara, M. (1982): Changes of blood glucose, insulin and lipids after castration. Bull. Egypt. Soc. Physiol. Sci., 2, 29-36.

19. Larson, Z., and Kowadlo-Silbergeld, A. (1965): Fat mobilizing effect of oestrogen. Acta Endocrinol., 48, 125-131.

20. Weil, C. (1983): The main indications of bromocriptine, in Clinical Report, Sandoz, Basel, pp. 11-13.

21. Horrobin, D.F. (1978): Prolactin: Effect and Clinical Significance, Vol. 6, Chapter 14, Churchil Livingstone Annual Research, pp. 77-78.

22. Segal, S., Polshuk, W., and Ben-David, M. (1976): Hyperprolactinemic male infertility. Fertil. Steril., 27, 1425-1427.

23. Segal, S., Yaffe, H., Laufer, N., and Ben-David, M. (1979): Hyperprolactinemia: effects on fertility. Fertil. Steril., 32, 556-600.

24. Thorner, M.O., Edwards, C.R.W., Hanker, J.P., Abraham, G., and Besser, G.M. (1977): Prolactin and gonadotropin interaction in the male, in The Testis in Normal and Infertile Men, ed. by Troen, P., and Naukin, H.R., New York, pp. 351-366.

25. Sheth, A.R., Mugatwala, R., and Sheth, G. (1975): Occurrence of prolactin in human semen. Fertil. Steril., 26, 905-907. 